\title{
NUMERICAL ANALYSIS OF CONTINUOUS CASTING OF NiTi SHAPE MEMORY ALLOY
}

\author{
Ternik, . $^{*} \&$ Rudolf, R.* $^{*}$ \\ ${ }^{*}$ Ternik Primož - Private Researcher, Bresterniška ulica 163, 2354 Bresternica, Slovenia \\ ${ }^{* *}$ University of Maribor, Faculty of Mechanical Engineering, Smetanova 17, 2000 Maribor, Slovenia \\ E-Mail: pternik@pt-rtd.eu, rebeka.rudolf@um.si
}

\begin{abstract}
The present study deals with the numerical analysis of the solidification process of NiTi binary alloy in a lab-scale continuous casting device. The physical medium is taken as an incompressible fluid where the heat is transferred by conduction and convection, including the thermal phase change phenomenon. The energy equation which includes both convection-diffusion heat transfer and a mushy region for the phase-change (solidification) is modelled by using an enthalpy-based formulation. The numerical approach is based on the finite volume method in body fitted coordinates with a SIMPLE scheme to couple the pressure and velocity fields.

Results show that the casting speed has a significant effect on the temperature distribution and, consequently on the solidification as well as metallurgical length. High casting speed may cause inadequate thickness of the solidified material at the mould exit to withstand the hydrostatic pressure of the molten NiTi below the mould and may also lead to breakout due to sticking of the solidified shell and mould because of lack of slag film for lubrication between the two.

(Received in December 2015, accepted in April 2016. This paper was with the authors 2 months for 1 revision.)
\end{abstract}

Key Words: NiTi, Solidification, Continuous Casting, Numerical Modelling, Heat Transfer

\section{INTRODUCTION}

The continuous development of science and technology in all industrial sectors means the connecting and usage of a wide range of new knowledge together with implementation of new modern technologies for production of materials with high functional, specific and special properties. Intermetallic Ni-Ti compound with shape-memory effect is an attractive material for applications in various branches of engineering, e.g. space technology, medicine, robotics and actuator technology [1-4].

Shape-Memory Alloys (SMA) are a group of materials characterised by the ShapeMemory Effect (SME) and superelasticity (SE), also called pseudoelasticity (PE) [5]. Ni-Ti binary alloys (sometimes called "Nitinol") are probably the best known from this group of materials. Nevertheless, these alloys are not always the most suitable for the particular purpose. This factor is also the reason for seeking optimised variants of these original binary systems. One of the possible solutions is to modify binary alloys by incorporation of one or more chemical elements into the production process. The resulting materials can be summed up in the term Ni-Ti-(X), where X means the presence of another element. Although the best memory characteristics are usually achieved for alloys with an Ni content of $49.3 \div 51$ at. \% [6], by decreasing the content of one element (Ti or Ni) to the prejudice of the third element, modified materials are obtained, while preserving some of original characteristics like corrosion resistance and related biocompatibility [7-9]. The intermetallic equiatomic compound of nickel and titanium thus remains as the base of modified binary materials. Nevertheless, it should be stated that the characteristics of Ni-Ti SMA may be modified significantly otherwise than by the appropriate choice of chemical composition, namely by forming and thermal (thermo-mechanical) processing. As a result, the final properties and products made of SMA are influenced significantly, not only by the chosen forming 
technique, but also their mutual sequence. These factors, together with the used technique play a major role in the manufacture of products from SMA [10].

Production of Ni-Ti alloys is done mostly by vacuum induction melting, whilst various melting procedures are used (electron beam melting, vacuum arc melting and plasma arc melting) [10]. When Ni-Ti alloys are melted, there can be unfavourable effects, especially of gases such as nitrogen or oxygen. Other problems consist in the conditions suitable for crystallization and minimization of micro- and macro-segregation connected with that. Also, contamination of the material has to be prevented by non-metallic intrusions. Due to the formation of titanium carbide and titanium oxide in $\mathrm{Ni}-\mathrm{Ti}$, the concentration of individual elements changes and thus so does the transformation temperature. Among other problems arising from the melting of $\mathrm{Ni}-\mathrm{Ti}$, there is the formation of the low-melting point phase $\mathrm{NiTi}_{2}$, which causes a strong tendency towards hot crack formation.

Although that the production process of SMA is very demanding, methods for rapid solidification (like melt spinning and continuous casting) are acceptable as well. These methods are characterised by high cooling rates, with a limited diffusion process during solidification and cooling. Such a fast cooling can lead to the formation of fine grain microstructure, less segregation and better homogeneity with little or no secondary phases. Consequently, in this way the produced SMA have better mechanical stability properties at elevated temperatures, better resistance to ageing and reduced fragility, as well as improved corrosion resistance.

This study, therefore, investigated the possibility of production simplicity by melting in a lab-scale continuous vertical casting machine. Since the experimental research during the rapid solidification process is usually limited, the solidification of NiTi alloy has been investigated by numerical simulations, which have become a very important approach for solving complex problems in engineering and science [11-14].

\section{NUMERICAL METHOD}

The governing equations were solved by taking the advantage of the standard finite volume method. Each governing equation is discretised in a space by integration over the set of control volumes forming the computational mesh. Such a process results in a system of linearized equations of mass, momentum and energy conservation joined with the constitutive equation. In these equations all variables are evaluated (and stored) in the centre of the control volumes populating the physical domain being considered. All, continuity, momentum, and energy equations were solved to tolerances $10^{-8}$.

In spite of some compelling features of the finite volume method there are some undesirable numerical effects (for example, artificial diffusion [15]) that are influenced by the low-order interpolation of the convection terms in governing equations. In order to overcome those undesirable numerical effects, the second-order accurate linear upwind differencing scheme [16] was used in the present study.

The rest of the paper is organised as follows. The necessary mathematical background and numerical details are presented Section 2 which is followed by the grid refinement and numerical accuracy assessment (Section 3). Following this analysis, the results are presented and subsequently discussed (Section 4). The main findings are summarised and conclusions are drawn in the final section of this paper.

\subsection{Solidification}

NiTi alloy solidification using ANSYS Fluent was modelled by the enthalpy-porosity technique $[17,18]$. In this technique the melt interface is not tracked explicitly. Instead, a 
liquid fraction, which indicates the fraction of the cell volume that is in liquid form, is associated with each cell in the computational domain.

The liquid-solid mushy zone is a region in which the liquid fraction values lie between 0 and 1 and its temperature ranges between the liquidus $\left(T_{l}\right)$ and solidus $\left(T_{s}\right)$ temperatures. The mushy zone is modelled as a "pseudo" porous medium in which the porosity decreases from 1 to 0 as the material solidifies. When the material has solidified fully the porosity becomes 0 and hence the velocities also drop to 0 .

The enthalpy of the material is computed as the sum of the sensible enthalpy $(h)$ and the latent heat $(\Delta H)$ :

$$
H=h+\Delta H=h_{r e f}+\int_{T_{r e f}}^{T} c_{p} d T+f_{l} L_{v}
$$

where $h_{r e f}$ is the reference enthalpy, $T_{r e f}$ the reference temperature, $c_{p}$ the specific heat at constant pressure, $f_{l}$ the liquid mass fraction and $L_{v}$ the latent heat of fusion.

The liquid volume fraction, $f_{l}$, is defined as:

$$
f_{l}=\left\{\begin{array}{cc}
1 & T>T_{l} \\
\left(T-T_{s}\right) /\left(T_{l}-T_{s}\right) & T_{s}<T<T_{l} \\
0 & T<T_{s}
\end{array}\right.
$$

Finally, for the solidification problem, the energy equation reads as:

$$
\frac{\partial}{\partial t}(\rho H)+\nabla \cdot(\rho \vec{v} H)=\nabla \cdot(k \nabla T)+S
$$

where $H$ is enthalpy, $\rho$ density, $\vec{v}$ fluid velocity, $k$ thermal conductivity, $T$ temperature, and $S$ source term:

$$
S=\rho L_{v} \frac{\partial f_{s}}{\partial t}+\rho L_{v} \vec{v}_{p u l l} \nabla f_{S}
$$

\subsection{Continuity and momentum equations}

The continuity equation is expressed as:

$$
\frac{\partial v_{i}}{\partial x_{i}}=0
$$

The enthalpy-porosity method assumes the mushy region (partially solidified region) as a porous medium. The porosity in each control volume is set equal to the liquid fraction in that control volume. In fully solidified regions, the porosity is equal to zero, which extinguishes the velocities in these regions. The momentum sink due to the reduced porosity in the mushy zone takes the following form:

$$
S=\frac{\left(1-f_{l}\right)^{2}}{\left(f_{l}^{3}+\varepsilon\right)} A_{m u s h}\left(\vec{v}-\vec{v}_{\text {pull }}\right)
$$

where $\varepsilon$ is a small number $(0.001)$ to prevent division by zero, $A_{m u s h}$ is the mushy zone constant that defines the gradient of the sink of fluid velocity when the porosity drops, and $\vec{v}_{p u l l}$ is the solid velocity due to the pulling of solidified material out of the domain (also referred to as the pull velocity).

Normally, the mushy zone constant range is $A_{\text {mush }}=10^{4} \div 10^{7}$. The greater the value of the mushy zone constant is the steeper is the transition of the velocity of the material to zero as it solidifies. 
The pull velocity is included to account for the movement of the solidified material as it is withdrawn continuously from the domain in the continuous casting process. The presence of this term in Eq. (6) allows newly solidified material to move at the pull velocity. If solidified material is not being pulled from the domain, $\vec{v}_{\text {pull }}=0$.

\subsection{Geometry, boundary conditions and assumptions}

The problem of the NiTi alloy solidification in the lab-scale device is depicted schematically in Fig. 1. The process starts by the transfer of molten NiTi to the water cooled copper mould, where it gets solidified into "semis" and subsequently pulled out into the final product.

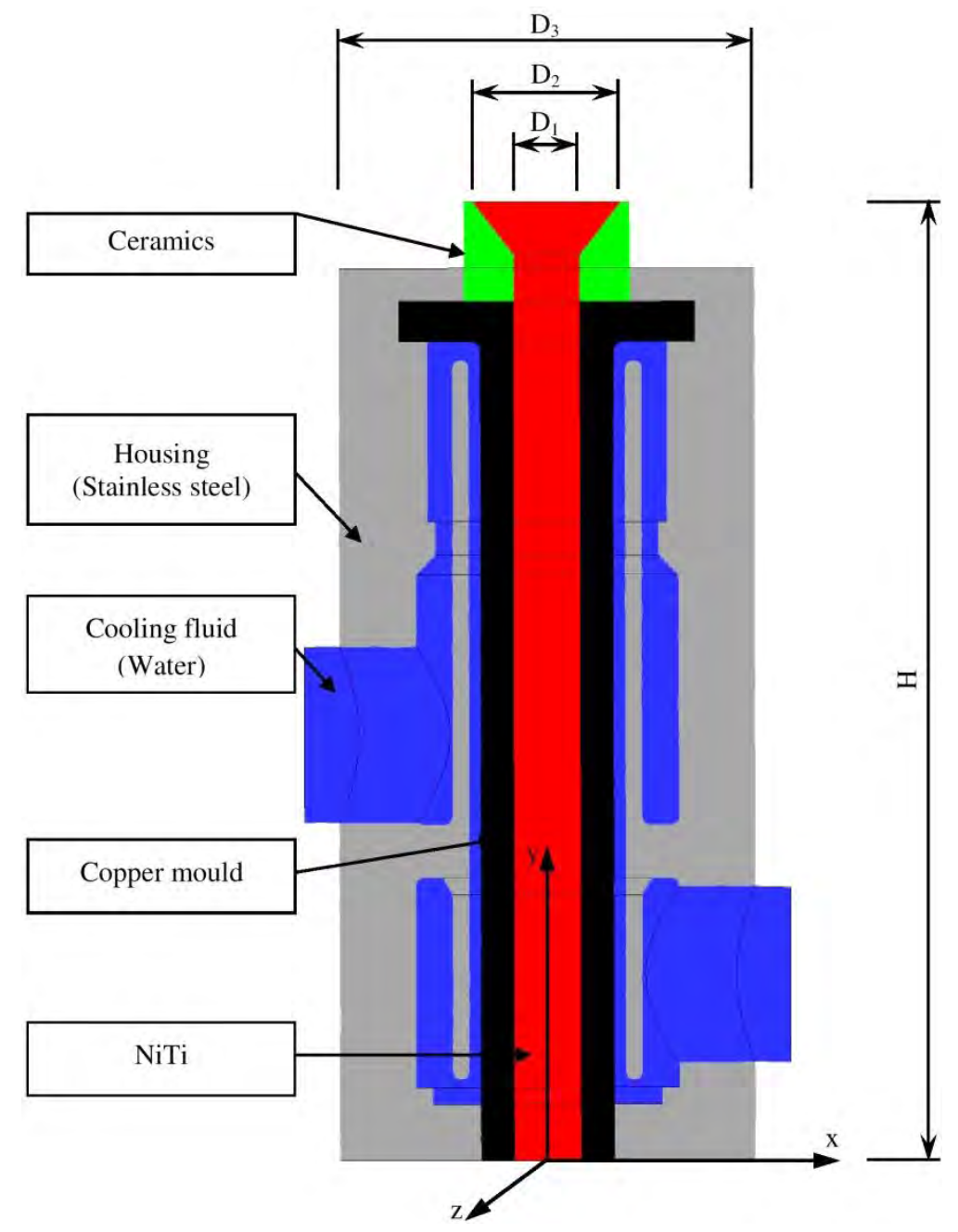

Figure 1: Schematic diagram of the simulation domain.

The cooling intensity of the mould should be high enough so that the NiTi solidifies to sufficient depth around the inner surface of the mould, forming a solid shell with the molten NiTi in the centre of the strand. Moreover, the solid shell formed should have an adequate amount of thickness to withstand the hydrostatic pressure of the molten NiTi.

Finally, the following assumptions were made during the numerical modelling:

- Liquid NiTi is an incompressible Newtonian fluid with invariant physical properties;

- Mould oscillation, effects of segregation, etc. have been ignored;

- Shrinkage due to solidification is ignored.

Based on the above assumptions, the material properties and operating conditions for the present numerical analysis are listed in Table I. 
Table I: Material properties and operating conditions.

\begin{tabular}{|c|c|}
\hline \multicolumn{2}{|c|}{ NiTi alloy [19] } \\
\hline Density & $6450 \mathrm{~kg} / \mathrm{m}^{3}$ \\
\hline Specific heat & $322 \mathrm{~J} / \mathrm{kg} \mathrm{K}$ \\
\hline Latent heat & $24200 \mathrm{~J} / \mathrm{kg}$ \\
\hline Thermal conductivity & $10 \mathrm{~W} / \mathrm{m} \mathrm{K}$ \\
\hline Viscosity & $0.00574 \mathrm{~Pa} \mathrm{~s}$ \\
\hline Solidus temperature & $1005.15 \mathrm{~K}$ \\
\hline Liquidus temperature & $1583.15 \mathrm{~K}$ \\
\hline Pull velocity & $\begin{array}{l}0.0025 \mathrm{~m} / \mathrm{s} \\
0.0050 \mathrm{~m} / \mathrm{s} \\
0.0075 \mathrm{~m} / \mathrm{s} \\
0.0100 \mathrm{~m} / \mathrm{s}\end{array}$ \\
\hline Casting temperature & $1693.15 \mathrm{~K}$ \\
\hline \multicolumn{2}{|c|}{ Cooling water } \\
\hline Flow rate & $101 / \mathrm{min}$ \\
\hline Density & $998.2 \mathrm{~kg} / \mathrm{m}^{3}$ \\
\hline Specific heat & $4182 \mathrm{~J} / \mathrm{kg} \mathrm{K}$ \\
\hline Thermal conductivity & $0.6 \mathrm{~W} / \mathrm{m} \mathrm{K}$ \\
\hline Viscosity & $0.001003 \mathrm{~Pa} \mathrm{~s}$ \\
\hline Temperature & $293.15 \mathrm{~K}$ \\
\hline \multicolumn{2}{|c|}{ Copper } \\
\hline Density & $8978 \mathrm{~kg} / \mathrm{m}^{3}$ \\
\hline Specific heat & $381 \mathrm{~J} / \mathrm{kg} \mathrm{K}$ \\
\hline Thermal conductivity & $387.6 \mathrm{~W} / \mathrm{m} \mathrm{K}$ \\
\hline \multicolumn{2}{|c|}{ Stainless steel } \\
\hline Density & $8030 \mathrm{~kg} / \mathrm{m}^{3}$ \\
\hline Specific heat & $502.48 \mathrm{~J} / \mathrm{kg} \mathrm{K}$ \\
\hline Thermal conductivity & $16.27 \mathrm{~W} / \mathrm{m} \mathrm{K}$ \\
\hline \multicolumn{2}{|c|}{ Ceramics } \\
\hline Density & $5600 \mathrm{~kg} / \mathrm{m}^{3}$ \\
\hline Specific heat & $446.3 \mathrm{~J} / \mathrm{kg} \mathrm{K}$ \\
\hline Thermal conductivity & $2.5 \mathrm{~W} / \mathrm{m} \mathrm{K}$ \\
\hline \multicolumn{2}{|c|}{ Ambient air } \\
\hline Temperature & $295.15 \mathrm{~K}$ \\
\hline $\begin{array}{l}\text { Convective heat } \\
\text { transfer coefficient }\end{array}$ & $10 \mathrm{~W} / \mathrm{m}^{2} \mathrm{~K}$ \\
\hline
\end{tabular}

\section{GRID REFINEMENT AND NUMERICAL ACCURACY STUDY}

A comprehensive evaluation of the CFD software used for particular application should be one of the goals of each theoretical as well as industrial numerical analysis. Such an evaluation should ensure that different types of errors are identified, treated separately and reduced below an acceptable level.

In an ideal world this would mean that solutions are provided for computational grids and time-steps, which are fine enough so that numerical errors can be neglected. But on the other hand, this is not a trivial task and the separation (as well as study) of errors is not always achieved but rather relies on previous studies [20]. Nevertheless, the worst strategy would be 
to avoid this subject and to provide solutions on a single computational grid, with a single time-step and with uncertainties in initial and boundary conditions not evaluated.

In the present work, the influence of computational grid refinement on numerical results was studied throughout the examination of spatial (grid) convergence using three different computational meshes (elements were concentrated towards each solid wall). With each grid refinement the number of elements in a particular direction is increased and element size is reduced. Such a procedure is useful (and encountered in many numerical studies [21-23]) for obtaining a higher-order estimate of the flow value (value at infinite grid) from a series of lower-order discrete values [24].

For a general variable $\varphi$ the grid-converged value (i.e. extrapolated to the zero element size) according to the Richardson extrapolation is given as:

$$
\varphi_{\text {ext }}=\varphi_{\text {MIII }}-\left(\varphi_{\text {MII }}-\varphi_{\text {MIII }}\right) /\left(r^{p}-1\right)
$$

where $\varphi_{M I I}$ is obtained on the finest grid and $\varphi_{M I I}$ is the solution based on the next level of coarse grid, $r=2$ is the ratio between the coarse to fine grid spacing and $p=2$ is the theoretical order of accuracy.

The numerical uncertainties for the normalised temperature $\left(T / T_{\text {casting }}\right)$ and the nondimensional vertical velocity $\left(v_{y}^{*}=v_{y} H / \alpha\right)$ on the horizontal plane $\mathrm{x}-\mathrm{y}$ of the copper mould are presented in Table II.

Table II: Grid refinement and numerical accuracy study $\left(v_{\text {pull }}=0.005 \mathrm{~m} / \mathrm{s}\right)$.

\begin{tabular}{|c|c|c|c|c|c|}
\cline { 2 - 6 } \multicolumn{1}{c|}{} & \multicolumn{5}{c|}{$x=0, y=0, z=0$} \\
\cline { 2 - 6 } \multicolumn{1}{c|}{} & Mesh $M I$ & Mesh $M I I$ & Mesh $M I I I$ & $\varphi_{\text {ext }}$ & Error \\
\hline$T / T_{\text {casting }}$ & 0.4540 & 0.4539 & 0.4538 & 0.4537 & $0.03 \%$ \\
\hline$v_{y}^{*}$ & -149.5598 & -149.6064 & -149.7680 & -149.8972 & $0.20 \%$ \\
\hline & \multicolumn{5}{c|}{$x=0, y=0, z=H / 2$} \\
\cline { 2 - 6 } & Mesh $M I$ & Mesh $M I I$ & Mesh $M I I I$ & $\varphi_{\text {ext }}$ & Error \\
\hline$T / T_{\text {casting }}$ & 0.5520 & 0.5518 & 0.5517 & 0.5516 & $0.03 \%$ \\
\hline$v_{y}^{*}$ & -149.5724 & -149.6060 & -149.6697 & -149.7207 & $0.08 \%$ \\
\hline
\end{tabular}

The results of calculations of the numerical accuracy (Table II) indicate that as the mesh is refined there is a consistent improvement in the accuracy of the predicted values, and the agreement between the predictions obtained with mesh MII and extrapolated values is extremely good for both flow variables under consideration (the discretisation error levels are smaller than $0.20 \%$ ). Based on this, the simulations in the remainder of the paper were conducted on mesh MII which provided a reasonable compromise between high accuracy and computational effort.

\section{RESULTS AND DISCUSSION}

\subsection{Velocity and temperature distribution}

The variation of temperature along the centre line and exit of the copper mould with different casting speeds is shown in Fig. 2. The different slopes in a particular curve are due to the change in cooling rate in different cooling zones. Furthermore, it can be noticed that the change in casting speed affects the temperature distribution significantly (increase in temperature as the casting speed increases), which, in turn, affects the solid shell thickness in the copper mould. 

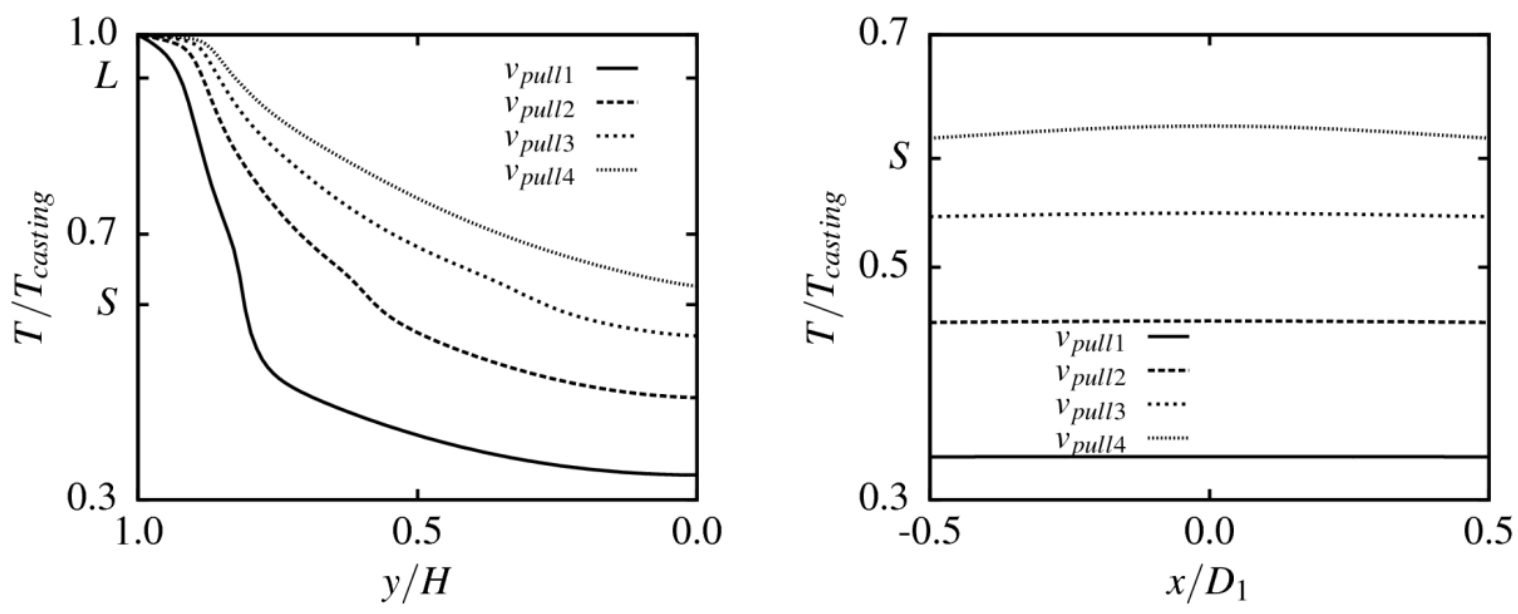

Figure 2: Temperature variation along the centre line (left) and exit (right) of the copper mould.

$v_{\text {pull } 1}=0.0025 \mathrm{~m} / \mathrm{s}, v_{\text {pull } 2}=0.0050 \mathrm{~m} / \mathrm{s}, v_{\text {pull }}=0.0075 \mathrm{~m} / \mathrm{s}, v_{\text {pull }}=0.0100 \mathrm{~m} / \mathrm{s}$, $S=$ solidus, $L=$ liquidus.

Consequently, the metallurgical length (i.e. the distance where the solidification is sufficiently complete) increases with an increase in casting speed and at the casting speed of $0.0100 \mathrm{~m} / \mathrm{s}$ metallurgical length became more than the computational domain and NiTi could not become completely solidified at the exit of the copper mould (Figs. 3 and 4).

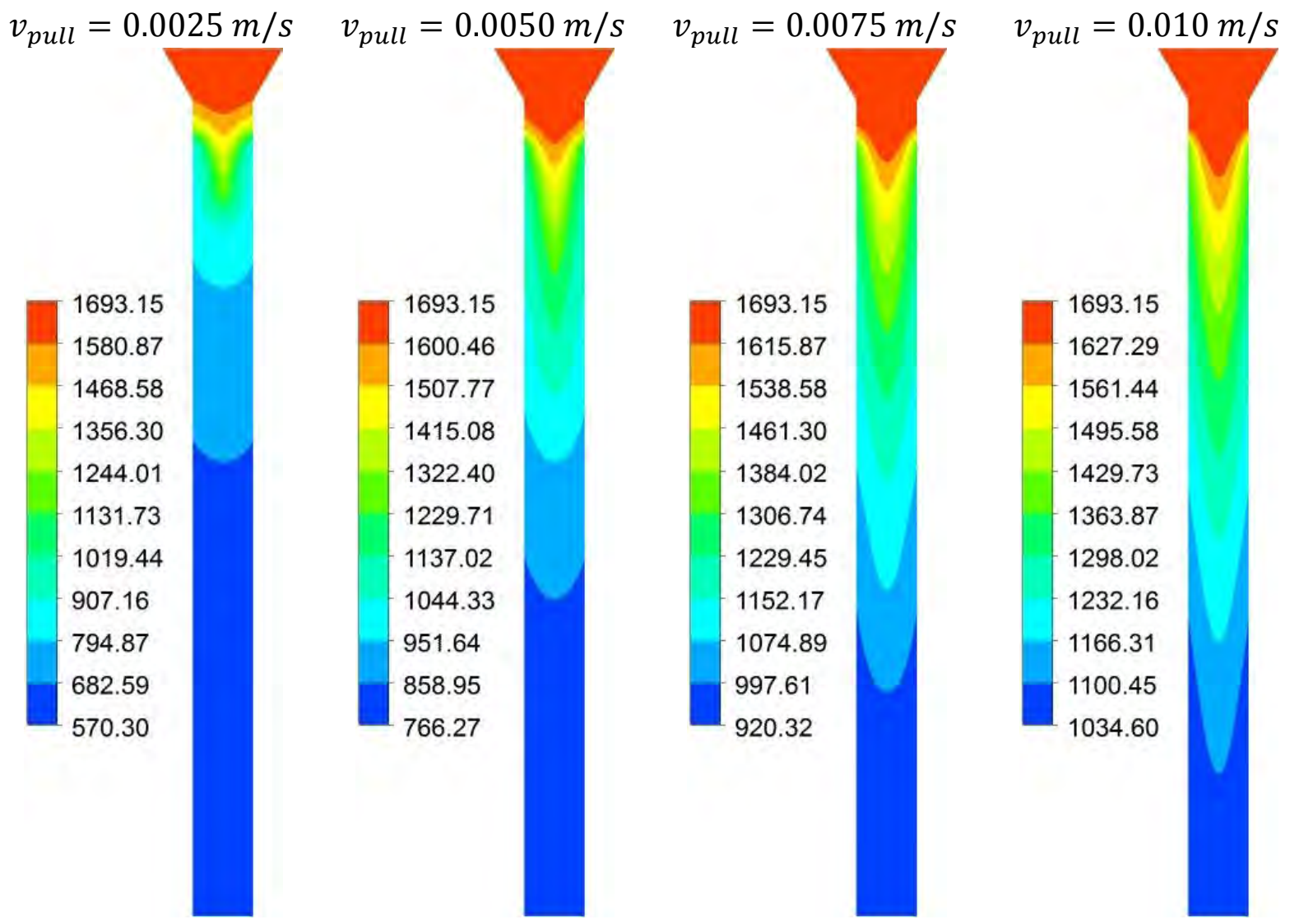

Figure 3: Temperature contour at different casting velocity.

Due to increased casting speed bulging, inner and surface cracks and other defects may be found in the final cast. In addition, high casting speed may cause inadequate thickness of the solidified material at the mould exit to withstand the hydrostatic pressure of the molten NiTi below the mould and may also lead to breakout due to the sticking of solidified shell and 
mould because of lack of slag film for lubrication between the two. So the casting speed is to be limited to prevent the formation of any defect.

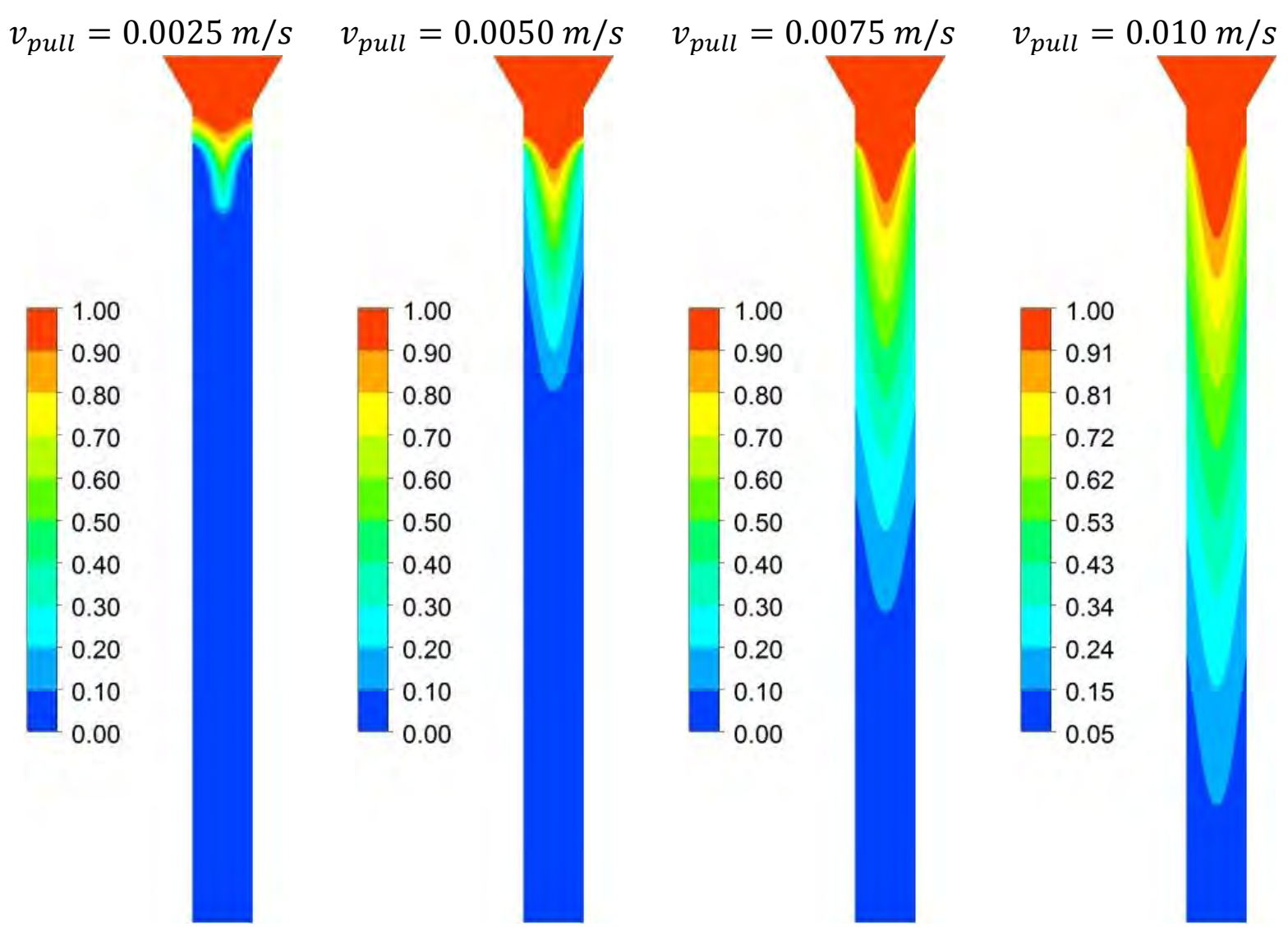

Figure 4: Liquid mass contour at different casting velocity.

\section{CONCLUSION}

In the present study the phase-change (solidification) of NiTi alloy in a lab-scale continuous casting device was studied by numerical means. The solidification process was modelled by the enthalpy-porosity method. The temperature and liquid NiTi mass fraction distribution has been calculated to study the effect of casting speed.

The influence of computational grid refinement on the numerical predictions was studied throughout the examination of grid convergence. By utilising extremely fine meshes the resulting discretisation error levels are below $0.20 \%$.

Based on the present numerical results, the following important conclusions can be emphasised:

- The different slopes in temperature variation is due to the change in cooling rate in different cooling zones;

- The change in casting speed affects the temperature distribution significantly (increase in temperature as the casting speed increases), which, in turn, affects the solid shell thickness in the copper mould;

- The metallurgical length increases with an increase in casting speed;

- For high casting speed the metallurgical length exceeds the computational continuous casting domain and NiTi may not become completely solidified at the exit of the mould;

- High casting speed may cause defects in the final cast, inadequate thickness of the solidified material;

- The casting speed is to be limited to prevent the formation of any defect; 
- The casting speed can be increased or decreased properly maintaining the cooling in the mould;

- Cooling rate can be lowered at a fixed casting speed by maintaining the metallurgical length and the temperature within the specified range.

\section{ACKNOWLEDGEMENT}

The research leading to these results was carried out within the framework of the Research Project "Biomedical shape memory alloys" (L2-5486) and has received funding from the Slovenian Research Agency (ARRS).

Last but not least, the authors are obliged to the very competent reviewers for their constructive and helpful comments and suggestions. These led to the improvements in the revised paper.

\section{REFERENCES}

[1] Mousavi, T.; Abbasi, M. H.; Karimzadeh, F. (2009). Thermodynamic analysis of NiTi formation by mechanical alloying, Materials Letters, Vol. 63, No. 9-10, 786-788, doi:10.1016/ j.matlet.2009.01.017

[2] Mehrabi, K.; Bruncko, M.; Kneissl, A. C. (2012). Microstructure, mechanical and functional properties of NiTi-based shape memory ribbons, Journal of Alloys and Compounds, Vol. 526, 45-52, doi:10.1016/j.jallcom.2012.02.097

[3] Ras, M. Y.; Ganesh, B. B. (2015). A real time experimental set up to analyse automatic actuation of a fire sprinkler using a shape memory alloy (NiTinol), Transactions of FAMENA, Vol. 39, No. $3,9-22$

[4] Ivanić, I.; Gojić, M.; Kožuh, S. (2014). Shape memory alloys (Part II): Classification, production and application, Chemistry in Industry: Journal of Chemists and Chemical Engineers of Croatia, Vol. 63, No. 9-10, 331-344, doi:10.15255/KUI.2013.017

[5] Ivanić, I.; Gojić, M.; Kožuh, S. (2014). Shape memory alloys (Part I): Significant properties, Chemistry in Industry: Journal of Chemists and Chemical Engineers of Croatia, Vol. 63, No. 910, 323-330, doi:10.15255/KUI.2013.016

[6] Raz, S. B.; Sadrnezhaad, S. K. (2004). Effect of VIM frequency on chemical composition, homogeneity and microstructure of NiTi shape memory alloy, Materials Science and Technology, Vol. 20, No. 5, 593-598, doi:10.1179/026708304225016680

[7] Duerig, T.; Pelton, A.; Stöckel, D. (1999). An overview of nitinol medical applications, Materials Science and Engineering: A, Vol. 273-275, 149-160, doi:10.1016/S0921-5093(99)00294-4

[8] Van Humbeeck, J. (2001). Shape memory alloys: A material and a technology, Advanced Engineering Materials, Vol. 3, No. 11, 837-850, doi:10.1002/1527-2648(200111)3:11 $\leq 837:$ :AID-ADEM837>3.0.CO;2-0

[9] Neslušan, M.; Mrkvica, I.; Čep, R.; Raos, P. (2012). Heat distribution when nickel alloy grinding, Technical Gazette, Vol. 19, No. 4, 947-951

[10] Kocich, R.; Szurman, I.; Kursa, M. (2013). The methods of preparation of Ti-Ni-X alloys and their forming, Braz Fernandes, F. M. (Ed.). Shape Memory Alloys - Processing, Characterization and Applications, InTech, Rijeka, doi:10.5772/50067

[11] Vukčević, V.; Werner, A.; Degiuli, N. (2012). Application of smoothed particle hydrodynamics method for simulating incompressible laminar flow, Transactions of FAMENA, Vol. 36, No. 4, 1 12

[12] Rek, Z.; Rudolf, M.; Zun, I. (2012). Application of CFD simulation in the development of a new generation heating oven, Strojniski vestnik - Journal of Mechanical Engineering, Vol. 58, No. 2, 134-144, doi:10.5545/sv-jme.2011.163

[13] Hsu, F. H.; Wang, K.; Huang, C. T.; Chang, R. Y. (2013). Investigation on conformal cooling system design in injection molding, Advances in Production Engineering \& Management, Vol. 8, No. 2, 107-115, doi:10.14743/apem2013.2.158 
[14] Edwin Raja Dhas, J.; Kumanan, S. (2013). Modeling and prediction of HAZ using finite element and neural network modeling, Advances in Production Engineering \& Management, Vol. 8, No. 1, 13-24, doi:10.14743/apem2013.1.149

[15] Versteeg, H. K.; Malalasekera, W. (1995). An Introduction to Computational Fluid Dynamics: The Finite Volume Method, Addison Wesley Longman Ltd., Harlow

[16] Shyy, W.; Thakur, S.; Wright, J. (1992). Second-order upwind and central difference schemes for recirculating flow computation, American Institute of Aeronautics and Astronautics Journal, Vol. 30, No. 4, 923-932, doi: $10.2514 / 3.11010$

[17] Voller, V. R.; Prakash, C. (1987). A fixed-grid numerical modelling methodology for convectiondiffusion mushy region phase-change problems, International Journal of Heat and Mass Transfer, Vol. 30, No. 8, 1709-1719, doi:10.1016/0017-9310(87)90317-6

[18] Prakash, C.; Samonds, M.; Singhal, A. K. (1987). A fixed grid numerical methodology for phase change problems involving a moving heat source, International Journal of Heat and Mass Transfer, Vol. 30, No. 12, 2690-2694, doi:10.1016/0017-9310(87)90152-9

[19] Introduction to shape memory alloys, from $h t t p: / / w w w . t i n i a l l o y . c o m / p d f / i n t r o d u c t i o n t o s m a . p d f$, accessed on 01-04-2016

[20] Ismail, M. I. S.; Afieq, W. M. (2016). Thermal analysis on a weld joint of aluminium alloy in gas metal arc welding, Advances in Production Engineering \& Management, Vol. 11, No. 1, 2937, doi: $\frac{10.14743 / \mathrm{apem} 2016.1 .207}{1}$

[21] Bilus, I.; Morgut, M.; Nobile, E. (2013). Simulation of sheet and cloud cavitation with homogenous transport models, International Journal of Simulation Modelling, Vol. 12, No. 2, 94-106, doi:10.2507/IJSIMM12(2)3.229

[22] Ternik, P.; Rudolf, R. (2014). Laminar forced convection heat transfer characteristics from a heated cylinder in water based nanofluids, International Journal of Simulation Modelling, Vol. 13, No. 3, 312-322, doi:10.2507/IJSIMM13(3)5.271

[23] Ternik, P.; Buchmeister, J. (2015). Buoyancy-induced flow and heat transfer of power law fluids in a side heated square cavity, International Journal of Simulation Modelling, Vol. 14, No. 2, 238-249, doi:10.2507/IJSIMM14(2)5.293

[24] Roache, P. J. (1994). Perspective: A method for uniform reporting of grid refinement studies, Journal of Fluids Engineering, Vol. 116, No. 3, 405-413, doi:10.1115/1.2910291 